\title{
Ejection Flow Dynamics Assessed by Ventricular Impulse and Elastance in the Human Hypertensive Heart
}

\author{
Makoto Suzuki, Mareomi Hamada, and Kunio Hiwada
}

\begin{abstract}
Left ventricular elastance is the intrinsic mechanical property of the chambers that generates pressure for a given volume, but the dynamics of the ejection flow are characterized by the ventricular impulse in early systole. The purpose of this study was to characterize the ejection dynamics in the human hypertensive heart according to the concept of ventricular impulse and elastance. Nineteen hypertensive patients without left ventricular hypertrophy (HT-I), 42 hypertensive patients with left ventricular hypertrophy (HT-II), and 43 normotensive subjects (NT) were studied by pulsed Doppler echocardiography. The maximum ejection force $\left(F_{\text {max }} ; k d y n e\right)$ and the end-systolic wall stress/end-systolic volume in$\operatorname{dex}\left(\mathrm{ESWS} / \mathrm{ESVI} ; \mathrm{kdyne} / \mathrm{cm}^{2} / \mathrm{ml} / \mathrm{m}^{2}\right)$ were examined as indexes of maximal impulse and elastance, respectively. $F_{\max }$ was calculated on the basis of the unsteady Bernoulli equation. With regard to impulse and elastance in NT, $F_{\max }$ was $43.7 \pm 6.1$ and ESWS/ESVI was $2.26 \pm 0.78$. In the hypertensive groups, HT-I showed normal $F_{\max }(46.0 \pm 5.5)$ with a significantly higher ESWS/ESVI $(3.52 \pm 1.12, p<0.01$ vs. NT), and HT-II showed a significantly lower $F_{\max }(34.4 \pm 7.2, p<0.01$ vs. NT) with normal ESWS/ESVI (2.65 \pm 1.38). There was a significant inverse correlation between $F_{\max }$ and left ventricular mass index $(r$ $=-0.45, p<0.001)$. This study shows for the first time the dissociation of maximum impulse and maximum elastance in the human hypertensive heart. The characteristics of elastance are well preserved, but those of the impulse are not preserved in the hypertensive hypertrophied heart. Further more, this dissociation is observed from the undetected hypertrophic state in the human hypertensive heart. (Hypertens Res 1994; 17: 123-131)
\end{abstract}

Key Words: hypertension, hypertrophy, Doppler flow dynamics, impulse, elastance

Both clinical (1-9) and experimental studies (10-18) of systolic functions in the pressure-dependent hypertrophied heart have yielded conflicting results. This controversy could be due to species differences, differences in the severity of myocardial hypertrophy, or differences in the variables measured in each study. Recently, using Doppler echocardiography, Isaaz and Pasipoularides (19) devised a noninvasive method to measure the left ventricular impulse that generates intraventricular pressure gradients (impulse gradients) and ejection flows. The new method seems to provide an improved insight into the significance of cardiac function in the hypertensive heart. The dynamics of ejection flow are characterized as a sudden imparting of momentum to the blood by the left ventricular impulse in early systole $(20-22)$. In contrast, the maximal left ventricular elastance $\left(E_{\max }\right)$, obtained from the endsystolic pressure-volume relationship, represents well the ventricular basal contractile state $(21-30)$ and is widely used as a sensitive indicator of left ventricular contractile function in various heart diseases.
With the advent of Doppler echocardiography, real-time flow dynamics in the heart can be studied $(19,31,32)$. However, to our knowledge, there have been no reports of studies done to assess cardiac functions from analysis of Doppler flow at the aortic annulus level in the human hypertensive heart. We have reported preliminary results regarding the ventricular impulse in the human hypertensive heart (33). In the present study, we used both quantitative M-mode and Doppler echocardiography to study patients with essential hypertension and normotensive control subjects. In particular, we measured the ventricular impulse and $E_{\max }$ to elucidate ejection flow dynamics in the hypertensive hypertrophied heart.

\section{Methods}

\section{Patient Population}

Sixty-one patients with uncomplicated essential hypertension (HT) (44 men and 17 women), aged 26 to 68 years $(50.3 \pm 10.1$ years, mean $\pm S D)$ participated in this study. Forty-three normotensive

From the Ehime University School of Medicine, Ehime, Japan.

Address for Reprints: Makoto Suzuki, The 2nd Department of Internal Medicine, Ehime University School of Medicine, Onsen-gun, Ehime 791-02, Japan.

Received October 14, 1993; accepted in revised form December 21, 1993. 
Table 1. Baseline Clinical Characteristics of Normotensive and Hypertensive Groups

\begin{tabular}{|c|c|c|c|}
\hline \multirow[b]{2}{*}{ Variable } & \multirow{2}{*}{$\begin{array}{c}\text { Normotensive } \\
\text { group (NT) } \\
(n=43)\end{array}$} & \multicolumn{2}{|c|}{ Hypertensive groups } \\
\hline & & $\begin{array}{c}\text { HT-I } \\
(n=19)\end{array}$ & $\begin{array}{c}\text { HT-II } \\
(n=42)\end{array}$ \\
\hline $\operatorname{Sex}(M / F)$ & $31 / 12$ & $12 / 7$ & $32 / 10$ \\
\hline Age (year) & $50 \pm 11$ & $51 \pm 8$ & $50 \pm 11$ \\
\hline $\operatorname{BSA}\left(\mathrm{m}^{2}\right)$ & $1.62 \pm 0.15$ & $1.59 \pm 0.15$ & $1.65 \pm 0.13$ \\
\hline $\mathrm{SBP}(\mathrm{mmHg})$ & $116 \pm 12$ & $157 \pm 11^{\#}$ & $160 \pm 12^{\#}$ \\
\hline DBP $(\mathrm{mmHg})$ & $72 \pm 10$ & $92 \pm 8^{\#}$ & $95 \pm 8^{\#}$ \\
\hline MBP $(\mathrm{mmHg})$ & $87 \pm 10$ & $113 \pm 8^{\#}$ & $117 \pm 8^{\#}$ \\
\hline HR (beats/min) & $66 \pm 10$ & $69 \pm 12$ & $65 \pm 11$ \\
\hline
\end{tabular}

Values are mean \pm SD. HT-I, hypertensive group without concentric cardiac hypertrophy; HT-II, hypertensive group with concentric cardiac hypertrophy. ${ }^{\#} p<0.01 v s$. NT. BSA, body surface area; SBP, systolic blood pressure; DBP, diastolic blood pressure, MBP, mean blood pressure; HR, heart rate.

subjects (31 men and 12 women), aged 30 to 66 years $(50.0 \pm 11.2$ years) $(\mathrm{NT})$, who were matched for age, sex, and body surface area were selected as controls (Table 1). Hypertension was diagnosed when the diastolic blood pressure was consistently $>$ $90 \mathrm{mmHg}$ in the outpatient clinic on at least three visits over one to two months. After admission, secondary types of hypertension were excluded by routine examinations. Patients with cardiac valvular disease, diabetes mellitus, or pulmonary disease were excluded. None had a history of chest pain or any signs or symptoms suggesting congestive heart failure. Hypertensive patients were divided into two groups: HT-I $(n=19)$ was the untreated hypertensive group without concentric cardiac hypertrophy, and HT-II $(n=42)$ was the untreated hypertensive group, which showed concentric hypertrophy of the heart. Concentric hypertrophy of the heart was defined as elevated relative wall thickness with an increased left ventricular mass index (estimated as more than 2 SD greater than the mean value in NT) (34).

\section{Echocardiography and Doppler Flow Variables}

M-mode, two-dimensional and pulsed Doppler echocardiographic examinations were done with an Aloka SSD870 imaging system (Tokyo, Japan) by standard techniques in all subjects (32). Left ventricular internal dimensions, and septal and posterior wall thickness were measured at end-diastole and end-systole, according to the recommendations of the American Society of Echocardiography (35), and used for measurement of all variables except left ventricular mass. Left ventricular mass was calculated according to the Penn convention (36, $37)$. Relative wall thickness was measured at end-diastole as the ratio of $2 \times$ posterior wall thickness/internal dimension (38). Left ventricular end-diastolic volume was estimated with Teichholz's formula (39). To record the velocity at the annulus level, the sample volume was placed into the aortic leaflets and gradually moved backward until the first clear ventricular outflow velocity was obtained. As shown in Fig. 1, pulsed Doppler echocardiographic analysis was done with a computer graphic analysis system (model CARDIO 500, Kontron Electronik, Munich, Germany), and peak velocity was measured. From the time-velocity derivative curve, peak acceleration, ejection time, and time intervals from the onset of upstroke of the flow velocity to the peak acceleration and to the peak velocity were obtained.

Stroke volume was calculated by multiplying the total flow velocity integral by the aortic valve area. Stroke work index, which is clinically the product of mean blood pressure and stroke volume index, was obtained as an index of left ventricular external work by the following equation:

Stroke work index $\left(\mathrm{gm} / \mathrm{m}^{2}\right)=0.0136 \times$ mean blood pressure $\times$ stroke volume index, where stroke volume index $=$ stroke volume/body surface area, mean blood pressure $=$ diastolic blood pressure + (systolic blood pressure - diastolic blood pressure) $/ 3$.

Intraobserver and interobserver correlations of duplicate measurements of peak velocity were $r=$ $0.98(n=35, p<0.001)$ and $r=0.92(n=35, p<$ 0.001 ), respectively. Intraobserver and interobserver correlations of duplicate measurements of peak acceleration were $r=0.97(n=35, p<0.001)$ and $r=$ $0.87(n=35, p<0.001)$, respectively.

Preload and Afterload Indexes of the Left Ventricle Left ventricular end-diastolic volume was used as an index of preload of the left ventricle. End-systolic meridional wall stress (ESWS) is reported to be the best index of afterload of the left ventricle $(5,7)$. ESWS was calculated on the basis of principles derived by Grossman et at. (40) and verified by Wilson et al. (41), with M-mode echocardiographic determination of left ventricular diameter and wall thickness, and cuff blood pressure obtained with a random-zero sphygmomanometer. In addition, peak systolic meridional wall stress (PSWS) was also computed with the standard formula (41).

\section{Maximum Impulse Index}

The impulsive mode of generator, which generates intraventricular pressure gradients and flows, is governed by the unsteady Bernoulli equation $(21,22)$. 
The impulse gradients $(P)$, which are early intraventricular and transvalvular gradients, consist of convective $(C)$ and local $(L)$ acceleration components $\left(P=C+L=A \times Q^{2}+B \times d Q / d t\right.$, where $Q$ is flow rate, $d Q / d t$ is rate of change of flow rate, and $A$ and $B$ are variables related to the geometry of the outflow tract and the ventricle) (22). According to Isaaz and Pasipoularides (19), the ejection force $(F)$, which generates impulse gradients, is calculated by the following equation:

$F=\rho \times S \times v^{2}+d / d t(\rho \times V \times k \times v)$,

where $\rho$ is blood density $\left(1.06 \mathrm{~g} / \mathrm{cm}^{3}\right), S$ is crosssectional area of the aortic annulus, and $v$ and $V$ are instantaneous outflow velocity and chamber volume. The factor $k$ is the scaling factor, which is dimensionless and remains approximately constant during ejection.

Equation (i) becomes:

$F=\rho \times S \times v^{2}+\rho \times k\{d V / d t \times v+V \times d v / d t\}$

Because the term $(d V / d t)$ means ejection volume per unit time, it is possible to rewrite the term $(-S$ $\times v)$.

So, the term $(V)$ can be obtained from

$V=L V E D V-S \int v d t$,

where $L V E D V$ is left ventricular end-diastolic volume. With substitution of equation (iii) and (iv) for $d V / d t$ and $V$, equation (ii) then becomes:

$F=\rho \times S \times v^{2}+\rho \times k \times\left[-S v^{2}+d v / d t(L V E D V-\right.$ $\left.\left.S \int v d t\right)\right]$

$=(1-k) \times \rho \times S \times v^{2}+k \times \rho \times\left(L V E D V-S \int v d t\right) \times$ $d v / d t$.

Pasipoularides (22) suggested that the ratio of aortic annulus cross section to inner wall surface area is a major geometric determinant of intraventricular ejection gradient. Therefore, it is necessary to correct this ventriculoannular disproportion gradient by the factor $k$. Isaaz et al. (19) simplified factor $k$ as $d^{2} / 4 R^{2}$ by solving the Laplace equation in the interior of the ventricle with Legendre polynomials and trigonometric identities, where $d$ is the aortic ring diameter and $\mathrm{R}$ is the radius of a sphere having the same volume as the ventricle. The peak value of $F\left(F_{\max }\right)$ is attained very early in ejection, and corresponds to the time of peak acceleration (19). Accordingly, $F_{\max }$ is calculated from equation (v) as follows:

$F_{\max }=(1-k) \times \rho \times S \times v a^{2}+k \times \rho \times\left\{L V E D V-\mathrm{S} \times \int_{o}^{\text {ta }}\right.$ $v(t) d t\} \times d v / d t_{\max }$

where $v a$ is $v$ at the time of peak acceleration, $t a$ is the time of peak acceleration, $d v / d t_{\text {max }}$ is the peak acceleration, and $S$ is calculated as $\pi d^{2} / 4$.

\section{Maximum Elastance Index}

The left ventricle has a time-varying elastance that is represented by the slope of the pressure-volume relationship curve during systole. It has been well appreciated that $E_{\max }$ is independent of wide variations in preload and afterload in a given inotropic state and is strongly correlated with basal contractility and inotropic state $(23-27,30)$. McKay et al. (29) have reported a good correlation between the true $E_{\max }$ calculated with the time-varying elastance model by Suga and Sagawa and the modified $E_{\max }$ obtained by single-point pressure-volume ratios.
However, wall thickness and chamber radius differ considerably in different diseases and stages of disease. Therefore, in this study, to correct for the variability in wall thickness and chamber radius, ESWS/ESVI was used as an index of maximum left ventricular elastance $(7,9,28)$. ESVI was calculated from the formula: ESVI $\left(\mathrm{ml} / \mathrm{m}^{2}\right)=$ left ventricular end-diastolic volume index - stroke volume index.

\section{Statistical Analysis}

All data are expressed as mean value \pm SD. Comparisons between two groups were performed by unpaired $t$-test, and differences among three goups were tested by one-way analysis of variance, followed by Duncan's test. Correlations between variables were assessed with univariate linear regression analysis and Pearson's correlation coefficient. Differences associated with $p$ values less than 0.05 were considered to be statistically significant.

\section{Results}

Echocardiographic Characteristics of Normotensive and Hypertensive Groups

Echocardiographic measurements are shown in Table 2. Both the interventricular septal wall and the posterior wall in HT-II were significantly thicker than those in NT and HT-I. No differences were observed among the three groups with regard to left ventricular end-diastolic or end-systolic diameters, or left ventricular end-diastolic volume index. Left ventricular mass index in HT-I was similar to that in NT, while left ventricular mass index in HT-II was significantly greater than that in NT. ESWS was significantly greater in HT-I than in NT, and that in HT-II was not significantly different from NT. PSWS was significantly greater in HT-I than in NT and HT-II. Stroke volume index was not statistically different among the three groups, but stroke work index was significantly higher in HT-I and HT-II than in NT.

Doppler Flow Variables in Normotensive and Hypertensive Groups

Doppler flow variables are shown in Table 3. Both peak velocity and peak acceleration were significantly lower in HT-II than in NT and HT-I, and there were no differences between the latter two. The time interval from the onset of the flow upstroke to the peak acceleration and to the peak velocity were significantly longer in HT-II than in NT and HT-I. Ejection time was not significantly different among the three groups. As shown in Fig. 2 , there was a significant inverse correlation between peak acceleration and left ventricular mass index $(r=-0.54, p<0.001)$.

\section{Maximum Impulse and Elastance Index}

Figure 3 shows ESWS/ESVI (upper panel) and $F_{\max }$ (lower panel) in NT, HT-I, and HT-II. ESWS/ESVI was significantly higher in HT-I $(3.52 \pm 1.12 \mathrm{kdyne} /$ $\left.\mathrm{cm}^{2} / \mathrm{ml} / \mathrm{m}^{2}\right)$ than in NT $\left(2.26 \pm 0.78 \mathrm{kdyne} / \mathrm{cm}^{2} / \mathrm{ml} /\right.$ $\left.\mathrm{m}^{2}\right)$ and HT-II $\left(2.65 \pm 1.38 \mathrm{kdyne} / \mathrm{cm}^{2} / \mathrm{ml} / \mathrm{m}^{2}\right)$, but that in HT-II was not significantly different from 
Table 2. Echocardiographic Characteristics of Normotensive and Hypertensive Groups

\begin{tabular}{|c|c|c|c|}
\hline \multirow[b]{2}{*}{ Variable } & \multirow{2}{*}{$\begin{array}{l}\text { Normotensive } \\
\text { group (NT) } \\
\quad(n=43)\end{array}$} & \multicolumn{2}{|c|}{ Hypertensive groups } \\
\hline & & $\begin{array}{c}\text { HT-I } \\
(n=19)\end{array}$ & $\begin{array}{c}\text { HT-II } \\
(n=42)\end{array}$ \\
\hline $\mathrm{Sa}\left(\mathrm{cm}^{2}\right)$ & $4.20 \pm 0.60$ & $4.47 \pm 0.52$ & $4.45 \pm 0.49$ \\
\hline $\operatorname{IVST}(\mathrm{cm})$ & $0.73 \pm 0.08$ & $0.78 \pm 0.09$ & $1.05 \pm 0.17^{\# \uparrow}$ \\
\hline PWTd $(\mathrm{cm})$ & $0.78 \pm 0.09$ & $0.82 \pm 0.06$ & $1.12 \pm 0.13$ \\
\hline
\end{tabular}
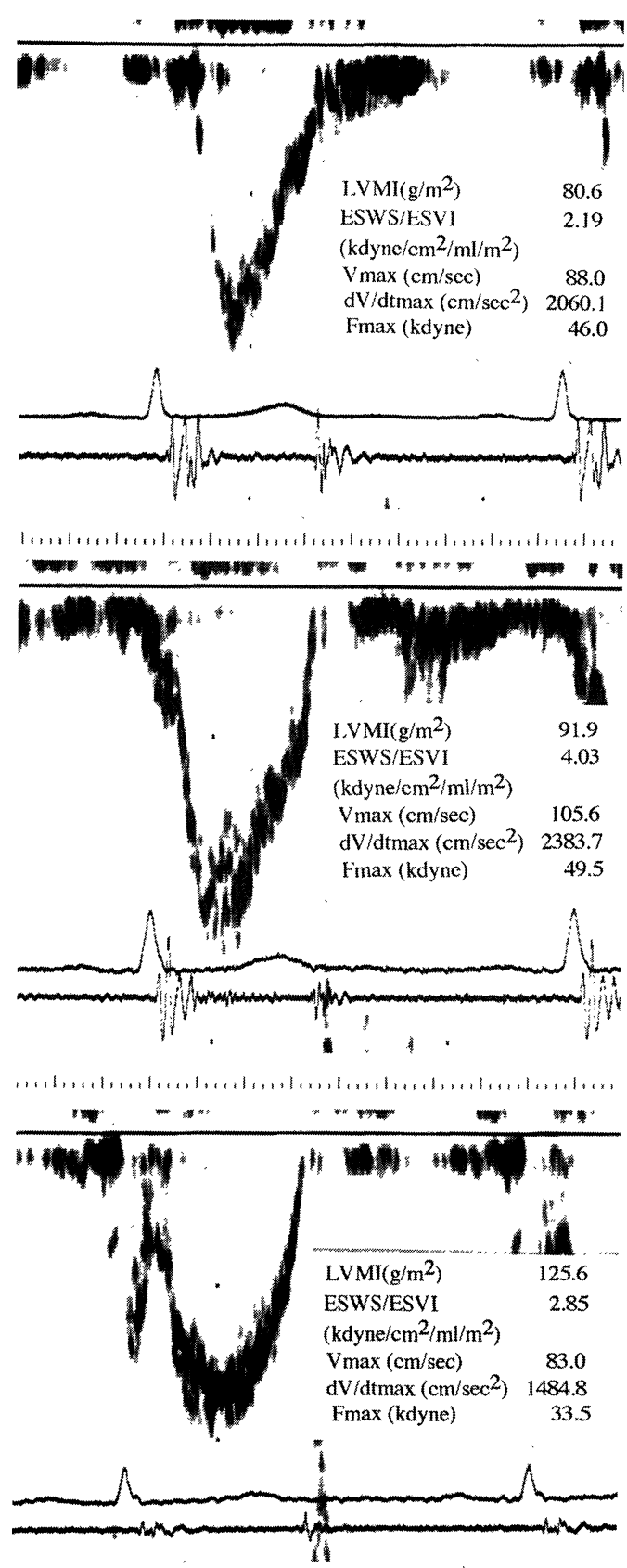

Fig. 5. Representative Doppler flow waveforms obtained from a normal subject (top), a patient in HT-I (middle) and a patient in HT-II (bottom). High ESWS/ESVI with normal $\mathrm{F}_{\max }$ in HT-I and normal ESWS/ESVI with low $\mathrm{F}_{\text {max }}$ in HT-II are observed.

intraventricular ejection pressure gradient. They

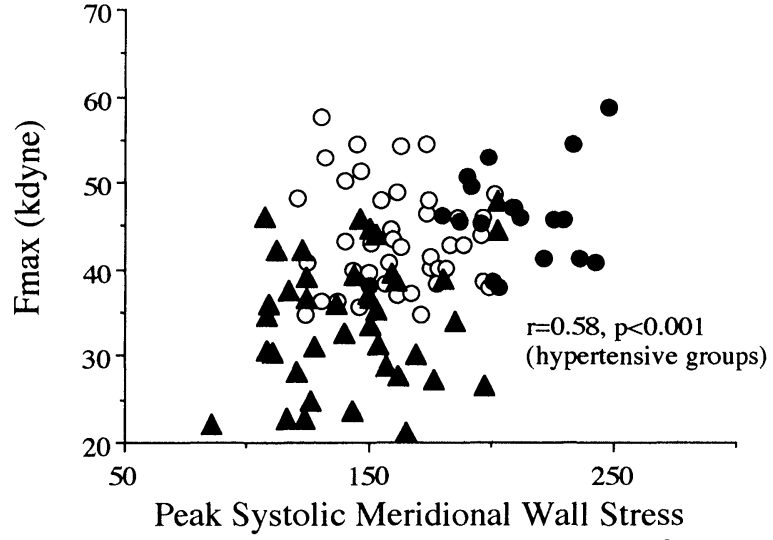

(kdyne $\left./ \mathrm{cm}^{2}\right)$

Fig. 6. Relationship between $\mathrm{F}_{\max }$ and PSWS. There is a significant positive correlation between the two variables, expecially in the hypertensive groups $(\mathrm{r}=0.58, \mathrm{p}<0.001)$. $\mathrm{Y}=17.6+1.24 \times 10^{-1} \mathrm{X}$. Open circles $(\mathrm{O})$ are $N T$, closed circles ( ) are HT-I and closed triangles ( $\mathbf{\Delta}$ ) are HT-II.

portion was also a geometric determinant of intraventricular ejection gradient, especially in the enlarged ventricle. In our study, Isaaz's equation (19), which is derived from the unsteady Bernoulli equation and corrects the ventriculoannular disproportion gradient with the factor $k$, was used to compute an index of the impulse. Our data analyzer, CARDIO 500, is different from Issaz's computer, but a normal value of $F_{\max }$ in our study is almost the same as that in Issaz's study.

With regard to the hypertensive heart, $F_{\max }$ in HT-I was normal, but that in HT-II was lower than that in the normotensive group. These findings imply that the hypertensive non-hypertrophied heart maintains a normal ventricular impulse at rest, but the hypertensive hypertrophied heart cannot maintain a normal ventricular impulse even at rest. As shown in Fig. $4, F_{\max }$ was significantly and inversely correlated with the left ventricular mass index. This result indicates that the ventricular impulse in the hypertensive heart gradually decreases in parallel with left ventricular hypertrophy. As in the report by Isaaz et al. (19), a strong positive correlation between $F_{\max }$ and peak acceleration was observed in the present study $(r=0.824, p<0.0001)$. Isaaz also suggested that peak acceleration was positively influenced by myocardial contractility and left ventricular end-diastolic volume, and negatively influenced by early ejection afterload (19). $F_{\max }$ is attained very early in ejection, so the left ventricular volume and wall thickness are close to their end- 
Time Velocity Curve

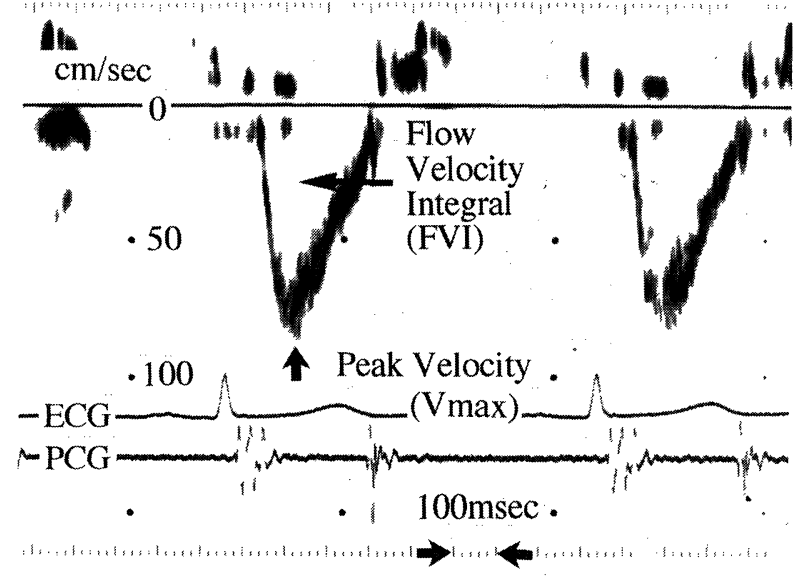

Time Velocity Derivative Curve

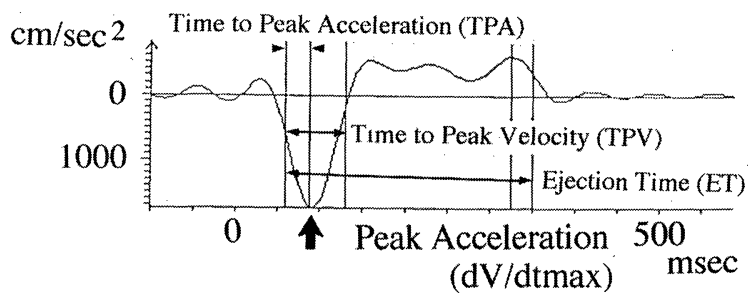

Fig. 1. Measurements of ejection flow waveform by pulsed Doppler echocardiography.

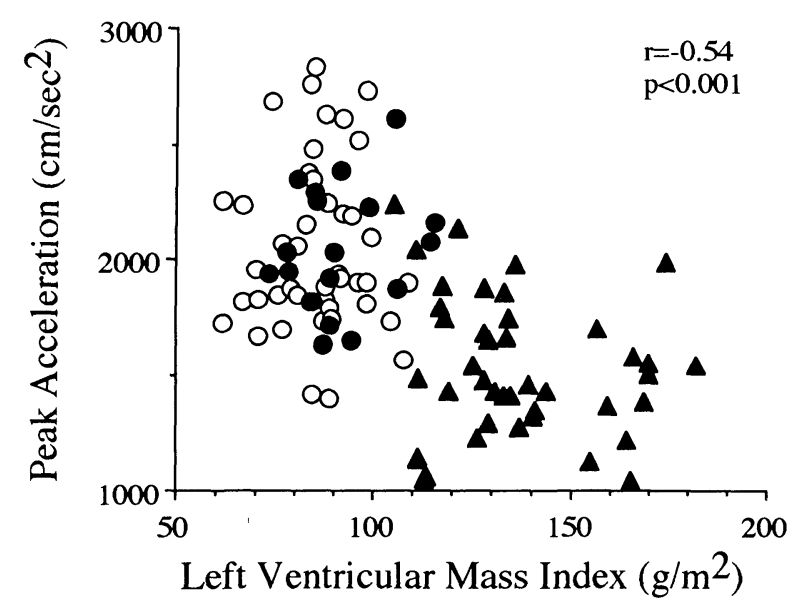

Fig. 2. Relationship between peak acceleration and left ventricular mass index. There is a significant inverse correlation between the two variables $(\mathrm{r}=-0.54, \mathrm{p}<0.001)$ : $\mathrm{Y}=2,660.3-7.68 \mathrm{X}$. Open circles $(\mathrm{O})$ are $N T$, closed circles (-) are HT-I and closed triangles (-) are HT-II.

of preserved ventricular elastance. In other words, the concentric hypertrophied heart can generate a high pressure for a given volume, but it cannot generate a normal acceleration of intraventricular blood. In contrast, the non-hypertrophied heart in hypertensive patients had supernormal elastance
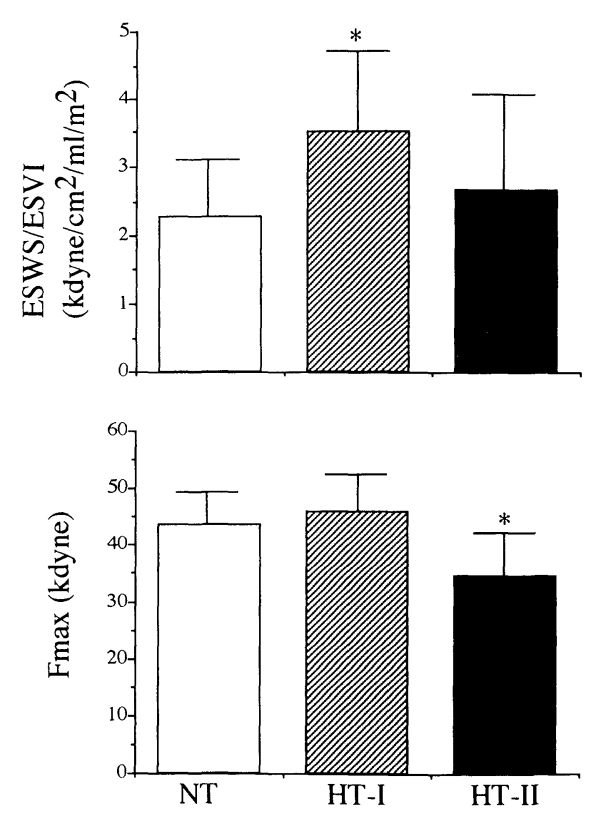

Fig. 3. Top panel: ESWS/ESVI in the three groups. Significantly higher ESWS/ESVI in HT-I and normal ESWS/ ESVI in HT-II are observed. Bottom panel: $\mathrm{F}_{\text {max }}$ in the three groups. Normal $\mathrm{F}_{\text {max }}$ in HT-I and significantly lower $\mathrm{F}_{\text {max }}$ in $H T$-II are observed. ${ }^{*} \mathrm{p}<0.01$ vs. $N T$.

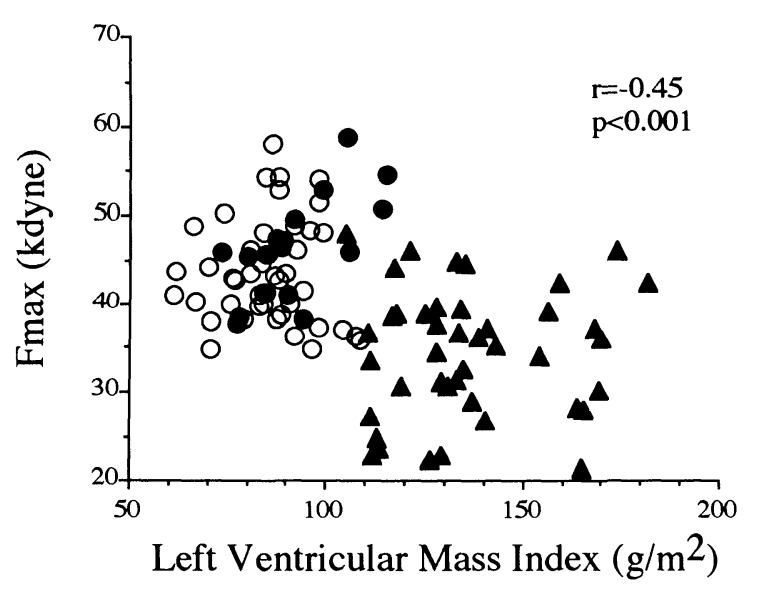

Fig. 4. Relationship between $\mathrm{F}_{\max }$ and left ventricular mass index. There is a significant inverse correlation between the two variables $(\mathrm{r}=-0.45, \mathrm{p}<0.001): \mathrm{Y}=54.0-$ $1.3 \times 10^{-1} \mathrm{X}$. Open circles $(\bigcirc)$ are $N T$, closed circles $(\bullet)$ are HT-I and closed triangles (-) are HT-II.

and could generate a normal impulse.

Impulse of the Hypertensive Heart

Rushmer (20) reported that left ventricular ejection is characterized by a sudden imparting of momentum to blood, in the form of high velocity in early systole, and he termed the ventricle the impulse generator. Pasipoularides et al. (21) showed that the ventricular impulse was generated by contraction of the left ventricular walls and was manifested as an 

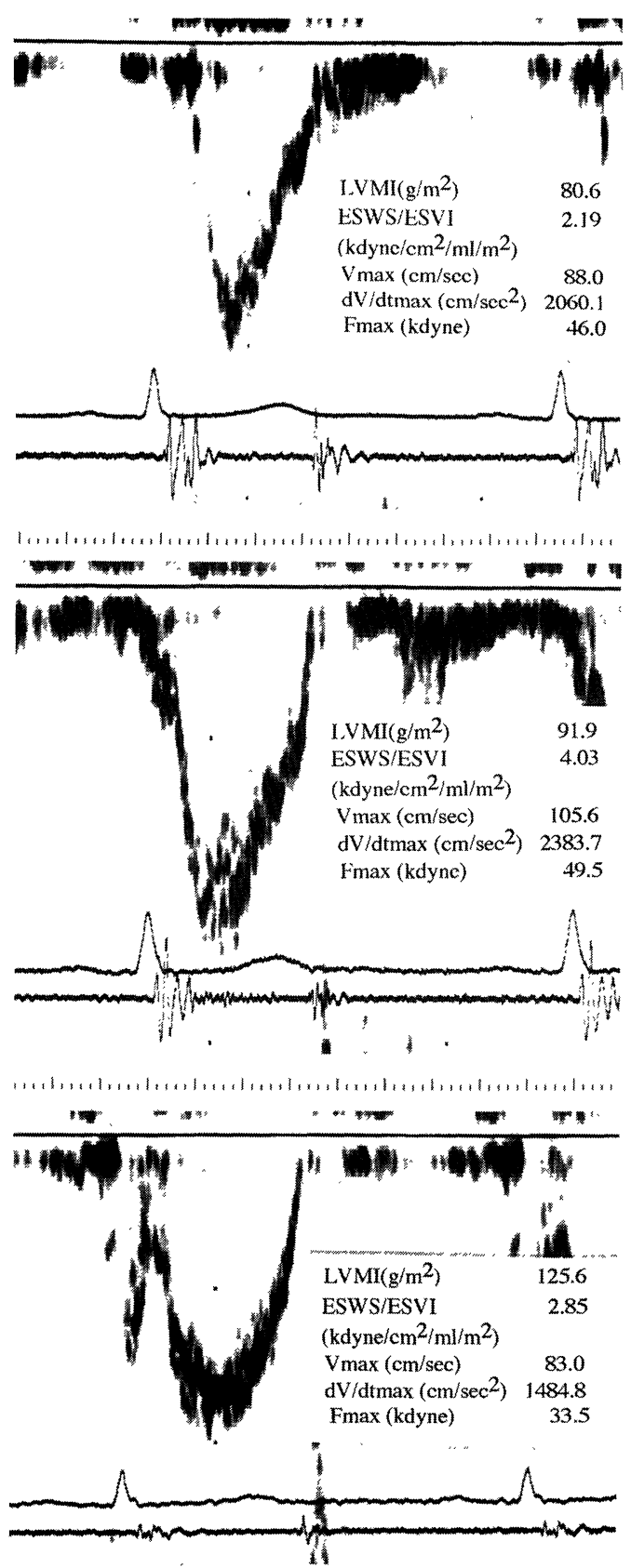

Fig. 5. Representative Doppler flow waveforms obtained from a normal subject (top), a patient in HT-I (middle) and a patient in HT-II (bottom). High ESWS/ESVI with normal $\mathrm{F}_{\max }$ in HT-I and normal ESWS/ESVI with low $\mathrm{F}_{\text {max }}$ in HT-II are observed.

intraventricular ejection pressure gradient. They termed this pressure gradient the impulse gradient. It embodies local acceleration and convective acceleration components on the basis of the unsteady Bernoulli equation. In their study, the impulse gradient consisted mainly of local acceleration components, which depended greatly on acceleration rather than on velocity. Furthermore, Pasipoularides (22) showed that the ventriculoannular dispro-

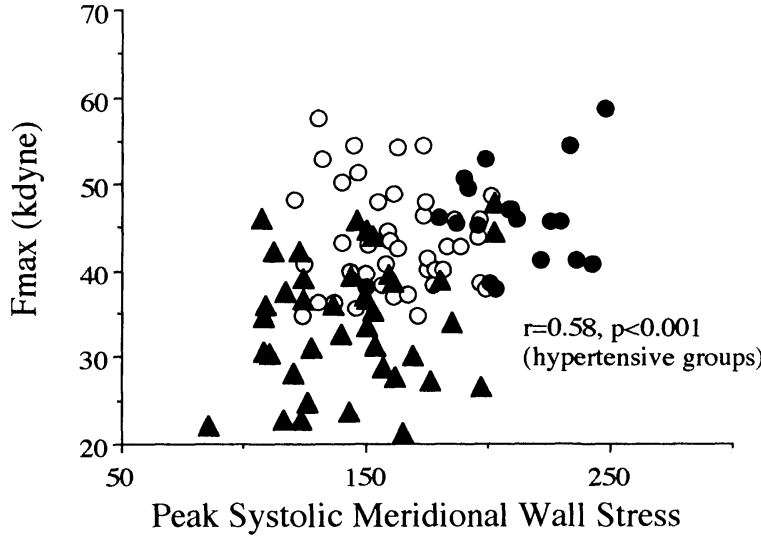

$\left(\mathrm{kdyne} / \mathrm{cm}^{2}\right)$

Fig. 6. Relationship between $\mathrm{F}_{\max }$ and PSWS. There is a significant positive correlation between the two variables, expecially in the hypertensive groups $(\mathrm{r}=0.58, \mathrm{p}<0.001)$ : $\mathrm{Y}=17.6+1.24 \times 10^{-1} \mathrm{X}$. Open circles $(\bigcirc)$ are $N T$, closed circles (-) are HT-I and closed triangles ( $\bullet$ ) are HT-II.

portion was also a geometric determinant of intraventricular ejection gradient, especially in the enlarged ventricle. In our study, Isaaz's equation (19), which is derived from the unsteady Bernoulli equation and corrects the ventriculoannular disproportion gradient with the factor $k$, was used to compute an index of the impulse. Our data analyzer, CARDIO 500, is different from Issaz's computer, but a normal value of $F_{\max }$ in our study is almost the same as that in Issaz's study.

With regard to the hypertensive heart, $F_{\max }$ in HT-I was normal, but that in HT-II was lower than that in the normotensive group. These findings imply that the hypertensive non-hypertrophied heart maintains a normal ventricular impulse at rest, but the hypertensive hypertrophied heart cannot maintain a normal ventricular impulse even at rest. As shown in Fig. $4, F_{\max }$ was significantly and inversely correlated with the left ventricular mass index. This result indicates that the ventricular impulse in the hypertensive heart gradually decreases in parallel with left ventricular hypertrophy. As in the report by Isaaz et al. (19), a strong positive correlation between $F_{\max }$ and peak acceleration was observed in the present study $(r=0.824, p<0.0001)$. Isaaz also suggested that peak acceleration was positively influenced by myocardial contractility and left ventricular end-diastolic volume, and negatively influenced by early ejection afterload (19). $F_{\max }$ is attained very early in ejection, so the left ventricular volume and wall thickness are close to their enddiastolic values. Thus, the early ejection afterload seems to correspond with PSWS. In the present study, there was a significant positive, rather than inverse, relationship between $F_{\max }$ and PSWS, as shown in Fig. 6. This means that concentric hypertrophy compensated for PSWS, but did not normalize $F_{\max }$ in HT-II. Therefore, the decrease in $F_{\max }$ in HT-II was not due to the increase in early systol- 
ic wall stress. In addition, there was no significant relationship between $F_{\max }$ and LVEDV or ESWS, and the myocardial contractility estimated by ESWS/ESVI in HT-II remained normal. Therefore, we cannot explain exactly why peak acceleration and $F_{\max }$ in HT-II were suppressed. To elucidate this mechanism, further studies are needed.

Analysis of early ventricular ejection dynamics by Doppler echocardiography was done to assess left ventricular performance. To our knowledge, the present study is the first application of left ventricular Doppler ejection variables in patients with hypertension. Peak acceleration values in NT were attained within about $28 \mathrm{msec}$ from the onset of the upstroke of flow velocity. This result is in accord with the finding of Pasipoularides et al. (21), which was about $25 \mathrm{msec}$. Doppler left ventricular ejection variables in HT-I were normal, but those in HT-II were low. It is known that inotropic stimulation augments the ventricular impulse and shortens the time from the onset to the peak of the impulse (20, 21). Therefore, the difference in ejection variables between HT-I and HT-II may reflect a difference in inotropic state. In addition, stroke volume index in HT-II was not significantly different from that in NT. This finding indicates that cardiac function in early systole is more sensitive to the cardiac condition of hypertensive patients than that in pansystole. Johnson et al. (42) have reported that despite the presence of a normal ventriculogram, patients with coronary artery stenosis have a depressed mean normalized systolic ejection rate during the first third of systole. The present findings and those reported by Johnson et al. indicate that variables measured early in ejection should be used to evaluate the cardiac condition in various cardiac diseases.

\section{Elastance of the Hypertensive Heart}

The elastic properties of the heart can ben expressed as the stress/strain ratio, which expresses the ability of the heart to return to its original shape and dimensions after deformation. In our study, ESWS / ESVI was used as an indirect index of myocardial contractility, and was independent of variations in the left ventricular end-diastolic volume index and ESWS. There are only a few reports on myocardial contractility in patients with hypertension in which the stress/strain relationship was used $(1,6-9)$. In the present study, ESWS/ ESVI was high in HT-I and normal in HT-II. These results are in agreement with previous studies (4-9), which show that hypertensive hearts without hypertrophy are in an increased inotropic state and hypertensive hearts with concentric hypertrophy remain in a normal inotropic state. Takahashi et al. (1) reported that in advanced left ventricular hypertrophy, in which left ventricular posterior wall thickness was more than $1.3 \mathrm{~cm}$, myocardial contractility was low. However, in their study, myocardial contractility remained normal in patients whose left ventricular posterior wall thickness was between $1.0 \mathrm{~cm}$ and $1.2 \mathrm{~cm}$, almost equal to that of HT-II in the present study. Thus, myocardial contractility may be preserved in hypertensive patients such as those in the present study. In more advanced left ventricular hypertrophy, myocardial contractility may be low. According to previous clinical and experimental studies $(5,16)$, increased sympathetic tone could play a key role in the increased inotropic state of the hypertensive non-hypertrophied heart, but the exact reason for the increased inotropic state in hypertensive patients without cardiac hypertrophy remains to be determined.

\section{Characteristics of Pump Function in the Hyperten- sive Heart}

In the present study, stroke volume index and stroke work index of the hypertensive heart were normal or high. These results agree with those of previous human studies $(2-8)$, which showed preservation of cardiac performance in the hypertensive heart. However, in the present study maximum impulse and maximum elastance were dissociated in the hypertensive heart.

Capasso et al. (13) examined isometric and isotonic contractions of papillary muscles from hypertensive hypertrophied rat hearts, and confirmed the dissociation of two commonly used measures of contractility, peak force development and velocity of shortening. Their study suggested that the hypertrophic myocardium might maintain ventricular performance in terms of force development while speed of shortening decreases. Considering their study, we think that there is a dissociation of the change of impulsive state and elastic state associated with hypertensive hypertrophy, and this dissociation begins while ventricular hypertrophy in the hypertensive heart in humans is still undetectable. The mechanism of the dissociation between the impulsive state and the elastic state has not been clarified. Further work is needed to clarify the mechanism of the link between the pressure overload state and the dissociation of impulse and elastance.

\section{Conclusion}

This study showed for the first time the dissociation of impulsive and elastic states in the hypertensive hypertrophic process in humans. The characteristics of elastance are well preserved, but those of the impulse are not preserved in the hypertensive hypertrophic heart. In addition, this dissociation starts during undetected hypertrophy in the hypertensive heart in humans.

\section{References}

1. Takahashi M, Sasayama S, Kawai C, Kotoura $\mathrm{H}$ : Contractile performance of the hypertrophied ventricle in patients with systemic hypertension. Circulation 1980; 62: 116-126.

2. Dreslinski GR, Messerli FH, Dunn FG, Frohlich ED: Early hypertension and cardiac work. Am J Cardiol 1982; 50: 149-151.

3. Devereux RB, Savage DD, Sachs I, Laragh JH: Relation of hemodynamic load to left ventricular hypertrophy and performance in hypertension. Am J Cardiol 1983; 51: 171-176. 
4. Wikstrand $\mathbf{J}$ : Left ventricular function in early primary hypertension. Functional consequences of cardiovascular structural changes. Hypertension 1984; 6 (suppl III): III-108-III-116.

5. Hartford M, Wikstrand JCM, Wallentin I, Ljungman SMG, Berglund GL: Left ventricular wall stress and systolic function in untreated primary hypertension. Hypertension 1985; 7: 97-104.

6. Lutas EM, Devereux RB, Reis G, et al: Increased cardiac performance in mild essential hypertension. Left ventricular mechanics. Hypertension 1985; 7: 979-988.

7. de Simone G, di Lorenzo L, Moccia D, Costantino G, Buonissimo S, de Divitiis O: Hemodynamic hypertrophied left ventricular patterns in systemic hypertension. Am J Cardiol 1987; 60: 1317-1321.

8. de Simone G, di Lorenzo L, Costantino G, Moccia D, Buonissimo S, de Divitiis O:Supernormal contractility in primary hypertension without left ventricular hypertrophy. Hypertension 1988; 11: 457-463.

9. Ganau A, Devereux RB, Pickering TG, et al: Relation of left ventricular hemodynamic load and contractile performance to left ventricular mass in hypertension. Circulation 1990; 81: 25-36.

10. Williams JF Jr, Potter RD: Normal contractile state of hypertrophied myocardium after pulmonary artery constriction in the cat. J Clin Invest 1974; 54: 1266-1272.

11. Sasayama S, Ross J Jr, Franklin D, Bloor CM, Bishop S, Dilley RB: Adaptations of the left ventricle to chronic pressure overload. Circ Res 1976; 38: 172-178.

12. Sasayama S, Franklin D, Ross J Jr: Hyperfunction with normal inotropic state of the hypertrophied left ventricle. Am J Physiol 1977; 232: H418-H425.

13. Capasso JM, Strobeck JE, Sonnenblick EH: Myocardial mechanical alterations during gradual onset longterm hypertension in rats. Am J Physiol 1981; 241: H435-H441.

14. Gwathmey JK, Morgan JP: Altered calcium handling in experimental pressure-overload hypertrophy in the ferret. Circ Res 1985; 57: 836-843.

15. Broughton A, Korner PI: Left ventricular pump function in renal hypertensive dogs with cardiac hypertrophy. Am J Physiol 1986; 251: H1260-H1266.

16. Gelpi RJ, Hittinger L, Fujii AM, Crocker VM, Mirsky I, Vatner SF: Sympathetic augmentation of cardiac function in developing hypertension in conscious dogs. Am J Physiol 1988; 255: H1525-H1534.

17. Weber KT, Janicki JS, Shroff SG, Pick R, Chen RM, Bashey RI: Collagen remodeling of the pressureoverloaded, hypertrophied nonhuman primate myocaridum. Circ Res 1988; 62: 757-765.

18. Bentivegna LA, Ablin LW, Kihara Y, Morgan JP: Altered calcium handling in left ventricular pressureoverload hypertrophy as detected with aequorin in the isolated, perfused ferret heart. Circ Res 1991; 69: 1538-1545.

19. Isaaz K, Pasipoularides A: Noninvasive assessment of intrinsic ventricular load dynamics in dilated cardiomyopathy. J Am Coll Cardiol 1991; 17: 112-121.

20. Rushmer RF: Initial ventricular impulse: a potential key to cardiac evaluation. Circulation 1964; 29: 268-283.

21. Pasipoularides A, Murgo JP, Miller JW, Craig WE: Nonobstructive left ventricular ejection pressure gradients in man. Circ Res 1987; 61: 220-227.

22. Pasipoularides A: Clinical assessment of ventricular ejection dynamics with and without outflow obstruction. J Am Coll Cardiol 1990; 15: 859-882.

23. Suga H, Sagawa K, Shoukas AA: Load indepen- dence of the instantaneous pressure-volume ratio of the canine left ventricle and effects of epinephrine and heart rate on the ratio. Circ Res 1973; 32: 314-322.

24. Suga H, Sagawa K: Instantaneous pressure-volume relationships and their ratio in the excised, supported canine left ventricle. Circ Res 1974; 35: 117-126.

25. Grossman W, Braunwald E, Mann T, McLaurin LP, Green LH: Contractile state of the left ventricle in man as evaluated from end-systolic pressure-volume relations. Circulation 1977; 56: 845-852.

26. Mehmel HC, Stockins B, Ruffmann K, Olshausen $\mathrm{KV}$, Schuler G, Kubler W: The linearity of the endsystolic pressure-volume relationship in man and its sensitivity for assessment of left ventricular function. Circulation 1981; 63: 1216-1222.

27. Sagawa K: The end-systolic pressure-volume relation of the ventricle: definition, modifications and clinical use. Circulation 1981; 63: 1223-1227.

28. Carabello BA, Spann JF: The uses and limitations of end-systolic indexes of left ventricular function. Circulation 1984; 69: 1058-1064.

29. McKay RG, Aroesty JM, Heller GV, Royal HD, Warren SE, Grossman W: Assessment of the endsystolic pressure-volume relationship in human beings with the use of a time-varying elastance model. Circulation 1986; 74: 97-104.

30. Kass DA, Maughan WL: From ' $E_{\max }$ ' to pressurevolume relations: a broader view. Circulation 1988; 77: 1203-1212.

31. Isaaz K, Ethevenot G, Admant P, Brembilla B, Pernot C, Chalon B: A new Doppler method of assessing left ventricular ejection force in chronic congestive heart failure. Am J Cardiol 1989; 64: 81-87.

32. Suzuki M, Hamada M, Sekiya M, Fujiwara Y, Sumimoto T, Hiwada K: Shortened deceleration time of early peak flow velocity in apparent normal transmitral Doppler flow in patients with dilated cardiomyopathy. Am J Noninvas Cardiol 1992; 6: 252256.

33. Suzuki M, Hamada M, Ohtani T, et al: Discrepancy between systolic elastance and flow generating capacity of concentric hypertrophied heart in hypertensive patients. J Am Coll Cardiol 1993; 21: 470A.

34. Ganau A, Devereux RB, Roman MJ, et al: Pattern of left ventricular hypertrophy and geometric remodeling in essential hypertension. J Am Coll Cardiol 1992; 19: 1550-1558.

35. Sahn DJ, DeMaria A, Kisslo J, Weyman A: The Committee on M-mode Standardization of the American Society of Echocardiography. Recommendations regarding quantitation in M-mode echocardiography: results of a survey of echocardiographic measurements. Circulation 1978; 58: 1072-1083.

36. Devereux RB, Reichek N: Echocardiograhpic determination of left ventricular mass in man: anatomic validation of the method. Circulation 1977; 55: 613-618.

37. Reichek N, Devereux RB: Left ventricular hypertrophy: relationship of anatomic, echocardiographic and electrocaridographic findings. Circulation 1981; 63: 1391-1398.

38. Reichek N, Devereux RB: Reliable estimation of peak left ventricuar systolic pressure by $\mathrm{M}$-mode echographic-determined end-diastolic relative wall thickness: identification of severe valvular aortic stenosis in adult patients. Am Heart $J$ 1982; 103: 202-209.

39. Teichholz LE, Kreulen T, Herman MV, Gorlin R: Problems in echocardiographic volume determinations: echocardiographic-angiographic correlations in 
the presence or absence of asynergy. Am J Cardiol 1976; 37: 7-11.

40. Grossman W, Jones D, McLaurin LP: Wall stress and pattern of hypertrophy in the human left ventricle. J Clin Invest 1975; 56: 56-64.

41. Wilson JR, Reichek N, Hirshfeld J, Keller CA: Noninvasive assessment of load reduction in patients with asymptomatic aortic regurgitation. Am J Med 1980; 68: 664-674.

42. Johnson LL, Ellis K, Schmidt D, Weiss MB, Cannon PJ: Volume ejected in early systole: a sensitive index of left ventricular performance in coronary artery disease. Circulation 1975; 52: 378-389. 